\title{
Role of osteogenic protein-I/bone morphogenetic protein-7 in spinal fusion
}

\author{
This article was published in the following Dove Press journal: \\ Orthopedic Research and Reviews \\ 5 October 2009 \\ Number of times this article has been viewed
}

\author{
Justin Munns \\ Daniel K Park \\ Kern Singh \\ Department of Orthopedic Surgery, \\ Rush University Medical Center, \\ Chicago, Illinois, USA
}

\begin{abstract}
Osteogenic protein-1 (OP-1), also known as bone morphogenetic protein-7 (BMP-7), is a protein in the TGF- $\beta$ family of cellular proteins that has shown potential for application in patients undergoing spinal fusion due to its proven osteoinductive effects, particularly in patients with spondylolisthesis. OP-1 initiates numerous processes at the cellular level, acting on mesenchymal stem cells (MSCs), osteoblasts, and osteoclasts to stimulate bone growth. Animal studies of OP-1 have provided strong evidence for the ability of OP-1 to initiate ossification in posterolateral arthrodesis. Promising findings in early clinical trials with OP-1 prompted FDA approval for use in long bone nonunions in 2001 and subsequently for revision posterolateral arthrodesis in 2004 under a conditional Humanitarian Device Exemption. Larger clinical trials have recently shown no notable safety concerns or increases in adverse events associated with OP-1. However, a recent clinical trial has not conclusively demonstrated the noninferiority of OP-1 compared to autograft in revision posterolateral arthrodesis. The future of OP-1 application in patients with spondylolisthesis thus remains uncertain with the recent rejection of Premarket Approval (PMA) status by the FDA (April 2009). Further investigation of its treatment success and immunological consequences appears warranted to establish FDA approval for its use in its current form.
\end{abstract}

Keywords: osteogenic protein-1, bone morphogenetic protein-7, spinal fusion

\section{Overview}

Posterolateral spinal arthrodesis is commonly used for the treatment of symptomatic degenerative spondylolisthesis. Spondylolisthesis refers to the slipping of one vertebrae relative to adjacent vertebrae, producing instability that often causes pain and radicular symptoms. Nonunion, however, is a well-documented complication of posterolateral spinal arthrodesis, with pseudarthrosis rates dependent in part on the number of vertebrae fused and type of fusion performed. ${ }^{1}$ Lack of fusion may ultimately compromise surgical outcomes by causing instability, persistent pain, and neurological symptoms in up to $57 \%$ of spinal surgery patients. ${ }^{2}$ To decrease the risk of pseudarthrosis, surgeons have incorporated various bone grafts, particularly iliac crest autograft. Procurement of iliac crest autograft, however, is fraught with morbidities including fracture, infection, hematoma, and chronic dysesthesias at the surgical site in $6 \%$ to $25 \%$ of patients. ${ }^{3,4}$ The possibility of using a graft substitute that is equivalent or better than autograft while eliminating donor site morbidity is therefore appealing to both patients and surgeons. Through the advances of molecular biology, bioactive substances such as recombinant human bone morphogenetic protein - also known as osteogenic protein-1 (OP-1) or bone morphogenetic protein-7 (BMP-7) - have
Correspondence: Kern Singh

Department of Orthopaedic Surgery,

Rush University Medical Center,

1725 West Harrison Street, POB I063,

Chicago, Illinois 60612, USA

$\mathrm{Tel}+\mathrm{I}(3 \mathrm{I} 2) 432-2373$

$\mathrm{Fax}+\mathrm{I}(312) 942-1516$

Email kern.singh@rushortho.com 
been utilized to augment bone healing through improved osteoinductive capacity in the hopes of eliminating the need for autograft bone harvest.

\section{Discovery}

The ability of devitalized bone to induce a cellular response and ultimately bone formation upon implantation was first discovered in 1965 by Dr Marshall Urist. ${ }^{5}$ Urist discovered that a group of osteogenic proteins, termed "bone morphogenetic proteins" (BMPs), were responsible for this phenomenon through a complex series of cellular events including cartilage formation, vascularization, bone formation, and eventually bone remodeling. ${ }^{6}$ This sequence of events was later found to result from the differentiation of pluripotent precursor cells along an osteogenic pathway. By 1988, research discoveries on BMPs had yielded a description of their molecular clones, an understanding of their biochemical activities, and a derivation of their amino acid sequence from a highly purified preparation of bovine bone. $^{7}$ These events led to the isolation and expression of the human complementary DNAs (cDNAs) of BMPs, which were recognized as members of the transforming growth factor- $\beta$ (TGF- $\beta$ ) family. In the past 20 years, researchers have developed a wider understanding of the molecular genetics of the TGF- $\beta$ superfamily and identified numerous group members that possess various degrees of inductive action toward bone or cartilage. One of the most prominent members of the TGF- $\beta$ superfamily with significant current clinical applications is OP-1.

\section{Biochemical structure and traits}

OP-1 is a member of the TGF- $\beta$ superfamily, which comprises a large number of growth and differentiation factors that share a high degree of homology within the C-terminal seven cysteine regions of their amino acid sequence. Its members include all of the BMPs, excluding BMP-1. ${ }^{8}$ All of the TGF- $\beta$ members form dimeric molecules. Each molecular subunit in the family contains three intra-chain disulfide bonds, with the units held together by a fourth bond. Almost all members of the family are synthesized as precursor molecules, with the pro-peptide being cleaved from the mature protein during secretion from the cell. ${ }^{9}$ Numerous growth and differentiation agents exist in bone matrix as either homodimers or heterodimers. Investigations have noted that the biological activity of heterodimers is superior to that of homodimers and that heterodimers cause a greater impact on growth, for reasons that are not currently understood. ${ }^{10}$
Similar to other members of the TGF- $\beta$ superfamily, OP-1/BMP-7 elicits cellular effects through a chain of events that begins with the interaction of specific transmembrane receptors present on the surface of stem and progenitor cells. The transmembrane receptors consist of both type I and type II serine/threonine receptor types. BMP ligands interact with these complexes in specific combinations to create a phosphorylated complex, as initial phosphorylation of a type II complex leads to type I phosphorylation and activation. This complex, in turn, activates phosphorylated receptor-regulated SMAD-signaling molecules. Mediator and inhibitor SMAD proteins closely regulate this intracellular SMAD-signaling pathway, the end product of which is an intra-nuclear protein complex that activates or represses target genes. Many of the targets of the pathway are transcription factors that possess the ability to regulate whole sets of genes upon induction. ${ }^{11,12}$ This pathway is subject to significant regulation at various levels. A co-activator, an antagonist, and multiple inhibitors contribute to extracellular regulation. Inhibitors are often upregulated by BMPs themselves, contributing to negative feedback. ${ }^{13}$ Numerous regulator SMAD proteins also closely control the SMAD pathway intracellularly (Figure 1).

Various members of the TGF- $\beta$ superfamily exhibit similar biochemical traits, but only a few have been proven to be independently osteoinductive. These osteoinductive members include BMP-2, BMP-9, and OP-1, the subject of the current review. The reason for the greater osteoinductive potential in this group has not been positively identified, though it is known that most of the other TGF- $\beta$ superfamily

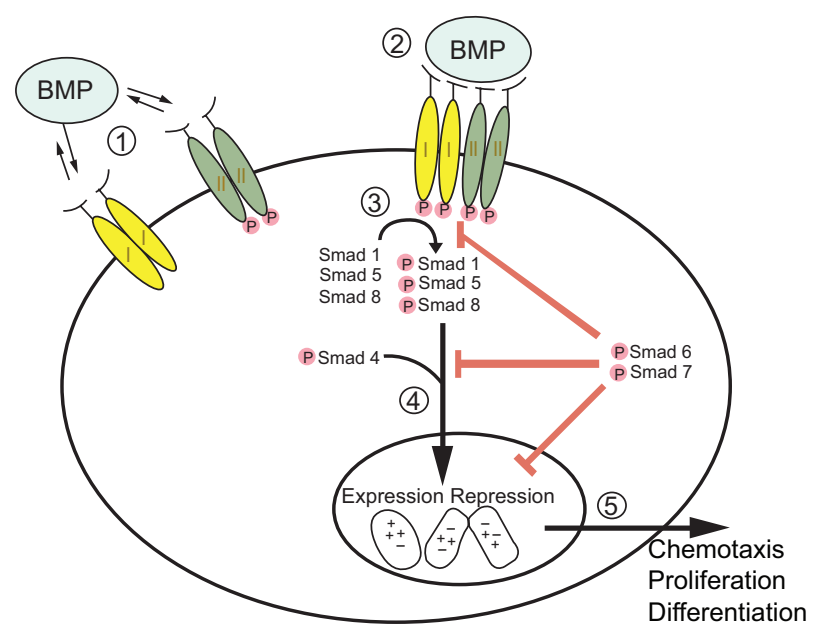

Figure I Mechanism of bone morphogenetic protein (BMP)-induced osteoinduction. A schematic of the signaling pathways involved in BMP-induced osteoinduction. Reproduced with permission from Walker DH, Wright NM. Bone morphogenetic proteins and spinal fusion. Neurosurg Focus. 2003; I3:1-13.54 Copyright (C 2003 American Association of Neurological Surgeons. 
members promote a later stage of osteoblast differentiation, from a pre-osteoblastic state into a functional osteoblast, compared to the more osteoinductive group members. In the normal healing process of a fracture, the predominant cell type present is pre-osteoblastic; therefore, most subsets of the TGF- $\beta$ superfamily can demonstrate osteoinduction of bone healing. ${ }^{9}$ During nonphysiologic fusion, however, the healing environment may not contain cells with a similar degree of differentiation.

\section{Mode of action}

Like the other members of the TGF- $\beta$ superfamily, OP-1 generates numerous effects at the cellular level. These proteins are essential for embryogenesis and organogenesis, with pleiotropic roles in cell growth, differentiation, migration, and apoptosis. ${ }^{14,15} \mathrm{OP}-1$, in particular, has been shown to play a critical developmental role in formation of the skeleton, kidney and eye, as demonstrated by the malformation or absence of these structures in null mutation knockout mice. ${ }^{16,17}$ It is now understood that receptors for OP-1 exist on a wide variety of cells, including mesenchymal stem cells (MSCs), osteoblasts, and osteoclasts. After the secondary messenger systems in the cytoplasm lead to the expression of response genes in the nucleus, several mechanisms lead either directly or indirectly to cellular chemotaxis, proliferation, and differentiation.

Processes at the cellular level demonstrate a dose-dependent response to BMP application. At lower concentrations, BMPs promote differentiation of MSCs into chondrocytes that help manufacture the cartilaginous matrix. This matrix then calcifies, undergoes vascularization, and remodels into mature bone in the process of endochodral ossification. At higher concentrations of osteogenic factor, BMPs initiate intramembranous bone formation. This bone demonstrates histology and biomechanical properties identical to physiologic bone, undergoing normal bone remodeling and fracture healing. ${ }^{18}$ The role of OP-1 in normal fracture healing has been confirmed by the upregulation of this factor during the early stages of fracture repair. ${ }^{19}$

The ability to undergo intramembranous ossification is significant when the clinical applications of OP-1 are considered. In the setting of posterolateral spinal fusions where bone formation is sought in a soft tissue environment that is not physiologic, OP-1 facilitates formation of a bony construct that might fulfill surgical goals. Delivery of supraphysiologic doses of OP-1 can result in more rapid bone creation by bypassing a cartilaginous precursor through intramembranous ossification, though certain factors can complicate the process. During bone formation, OP-1 has demonstrated sufficient osteoinductive effect to overcome nicotine in spinal fusion of rabbits and to initiate bone growth in estrogen-deficient animals, in a dose-dependent fashion..$^{20-23}$

\section{Delivery}

The method by which OP-1 is delivered holds critical importance in ensuring that the desired effect on bone growth is achieved. BMPs act locally near the site of application. A high dose is necessary in order to stimulate bone formation over time, and providing an effective dose has proven to be the rate-limiting step toward clinical application of OP-1. ${ }^{24}$

Two basic strategies have been used in the delivery of OP-1 to the sites of action. The indirect approach involves transduction of local cells to produce considerable amounts of OP-1 for local bone fusion through gene therapy. Theoretically, this technique should provide sustained amounts of BMP through local cells without the need for direct delivery by a carrier. Questions still remain about the safety and efficacy of this treatment method as it is still in its infancy.

The direct method, however, delivers recombinant protein to the area of bone formation with or without a carrier. To maintain a high concentration of OP-1, an ideal carrier must have several key properties: it must bind OP-1, protect the protein from degradation, maintain its bioactivity while releasing it for local activity in a controlled manner, and act in a biodegradable and osteoconductive fashion. ${ }^{24,25}$ Because BMP molecules are relatively soluble, less soluble carriers are used to maintain the substance at the site of fusion in sufficient concentration. These carriers can either demonstrate more structural, space-occupying properties (calcium phosphate ceramics or synthetic polymers) or provide less stability and space maintenance (type I collagen sponge). ${ }^{26,27}$

A carrier of many clinical BMP formulations, type I collagen is usually manufactured from porcine or bovine skin/ bone as a sponge or absorbable sheet, sometimes combined with calcium phosphate ceramics to form structural scaffolds. It is known to possess good biocompatibility, to degrade into physiologically compatibile byproducts, and to interact safely with macromolecules. Additional advantages of using the type I collagen sponge or sheet are its versatility, ease of manipulation, and ability to maintain function when wetted. ${ }^{25}$ Collagen carriers are, however, particularly susceptible to changes in $\mathrm{pH}$, as modification of the isoelectric point can cause a 100-fold variation in the substance's ability 
to retain the protein. ${ }^{28}$ Type I collagen is employed in the OP-1 Putty used in clinical trials under limited FDA approval (as discussed in 'FDA approval' section), along with recombinant human OP-1, carboxymethylcellulose, and saline. Furthermore, carboxymethylcellulose also serves a critical role in delivering the graft substitute by modifying the formula's viscosity and retaining water so that the carrier remains intact. Overall, this matrix material promotes a biologic response to the osteoinductive properties of OP-1 by controlling its retention time, localizing its activity, and providing a region for the bone formation processes to occur.

\section{Production techniques}

OP-1 is manufactured for clinical applications using recombinant DNA biotechnology processes that take advantage of mammalian cell expression. To generate a production cell line, the relevant BMP DNA coding sequence is placed in a vector system with the appropriate promoter/enhancer and a selectable marker. The vector is transfected into Chinese hamster ovary cells, which then amplify the sequence until many copies reside in the cell. The cell supernatant, containing the numerous secreted OP-1 proteins, is then assessed for purity. It is processed through a series of steps, grown in sequentially larger volumes of culture medium, fermented, and finally purified from the conditioned medium. The quality of this medium is verified before it is stored. Once released, the OP-1 product is further processed as part of the formulation. ${ }^{9,29}$

Recombinant human OP-1 and bovine collagen are first produced independently. Subsequently, they are mixed together, dried, and terminally sterilized with high-dose ( $25 \mathrm{kGy}) \gamma$-irradiation. The use of $\gamma$-irradiation for sterilization of OP-1 Putty components is distinct, for none of the currently FDA-approved recombinant BMP products use this technique. The irradiation dosage is the most effective method to sterilize microorganisms - both viruses and bacteria - during processing and ward off even greater levels of immunogenicity than are already present. $\gamma$-irradiation is typically avoided since proteins can undergo denaturation and truncation (through breakage of covalent bonds) as well as oxidation, deamination, and other unfavorable effects. After irradiation, these components are joined with sterile dried putty additive, including carboxymethylcellulose and saline, before final packaging. Notably, the OP-1 implant used for tibial nonunions does not include carboxymethylcellulose, as compared to the OP-1 Putty used in posterolateral arthrodesis.

\section{Preclinical studies}

A variety of preclinical studies performed in animal models preceded the introduction of human clinical trials used to assess the effectiveness of OP-1. The healing of a spinal fusion is a multifactorial process, which complicates analysis in the clinical setting. Because success or failure of an arthrodesis is difficult to judge noninvasively, an animal model represents a practical solution to studying individual factors involved in the complex process. ${ }^{30}$ Animal models also allow for a greater degree of control over variables than is typically not feasible with human subjects, including the use of systemic agents, surgical technique, and genetic factors. ${ }^{31}$ Outcomes can also be precisely measured using animal models. While a variety of different animals have served as subjects for demonstration of osteoinductive capacity (ie, as proof of concept models), rabbits and canines have been used most frequently to demonstrate the applicability of OP-1 for posterolateral spinal fusions in humans.

Numerous animal investigations of lumbar fusion have been performed using recombinant human OP-1 (Table 1). OP-1 was used as a graft substitute in adult canines for posterior spinal fusion by Cook and colleagues. ${ }^{32}$ The authors found stable fusions (both radiographically and histologically) in the study group by 6 weeks, with complete fusion present by 12 weeks postimplantation. In contrast, the control (autograft) group demonstrated fusion at 26 weeks. Similarly, Magin and Delling used recombinant human OP-1 for interbody fusion after L4-5 disc removal in sheep. ${ }^{33}$ CT, MRI, bone scintigraphy, biomechanical testing, and histology were used to assess fusion. The OP-1 demonstrated superior fusion rates to autograft and hydroxyapatite groups. Grauer and colleagues also performed similar experiments in rabbits. ${ }^{34}$ Thirty-one rabbits were divided into 3 study groups: autograft, carrier alone, and carrier with OP-1. Evaluation of fusions by manual palpation, radiographs, and mechanical/ histological analysis demonstrated superior bone formation in the OP-1 group (100\%) compared to the autograft group $(63 \%)$. The carrier group showed no bone formation. Additionally, radiographs were only 55\% sensitive and 92\% specific in determining fusion.

Investigation of whether the inhibitory effects of nicotine on spinal fusion could be overcome by OP-1 was examined by Patel et al. ${ }^{35}$ The investigators performed single-level posterolateral intertransverse process fusions at the L5-6 level on rabbit subjects, using either OP-1 or autograft. Nicotine was administered via subcutaneous mini-osmotic pumps. Fusion rate was $25 \%$ for subjects exposed to nicotine with autograft, compared to $100 \%$ exposed to nicotine with OP-1, 
Table I Animal investigations of lumbar fusion performed using recombinant human OP-I

\begin{tabular}{|c|c|c|c|c|c|}
\hline Investigators & Year & Species & Method & Evaluation & Key conclusions \\
\hline Cook et a ${ }^{32}$ & 1994 & Canines & $\begin{array}{l}\text { Defects were created in tibia or } \\
\text { ulna in subjects, then filled with } \\
\text { OP-I + collagen carrier, carrier } \\
\text { alone, autograft, or left unfilled }\end{array}$ & $\begin{array}{l}\text { Radiographs, histological } \\
\text { evaluation, mechanical } \\
\text { testing }\end{array}$ & $\begin{array}{l}\text { Solid fusion in OP-I subjects at } \\
6 \text { weeks; fusion of autograft } \\
\text { subjects at } 26 \text { weeks }\end{array}$ \\
\hline $\begin{array}{l}\text { Magin and } \\
\text { Delling }\end{array}$ & 1999 & Sheep & $\begin{array}{l}\text { Posterior lumbar interbody fusion } \\
\text { after discectomy in } 3 \text { groups: auto- } \\
\text { graft, deproteinized bovine hydroxyl } \\
\text { apatite, OP-I on collagen carrier }\end{array}$ & $\begin{array}{l}\mathrm{CT}, \mathrm{MRI} \text {, bone scintigraphy, } \\
\text { biomechanical testing, } \\
\text { histological evaluation }\end{array}$ & $\begin{array}{l}\text { OP-I subjects demonstrated } 80 \% \\
\text { fusion at } 4 \text { months, } 60 \% \text { increase } \\
\text { in bone formation (with improved } \\
\text { quality) compared to other groups }\end{array}$ \\
\hline Grauer et $\mathrm{al}^{134}$ & 2000 & Canines & $\begin{array}{l}\text { Intertransverse process lumbar } \\
\text { fusion in } 3 \text { groups: autograft alone, } \\
\text { carrier alone, OP-I with carrier }\end{array}$ & $\begin{array}{l}\text { Manual palpation, } \\
\text { radiographs, mechanical } \\
\text { analysis, histological } \\
\text { evaluation }\end{array}$ & $\begin{array}{l}\text { Superior bone formation in OP-I } \\
(100 \%) \text { vs autograft (63\%) group, } \\
\text { with no bone formation in carrier } \\
\text { alone group; radiographs only } 55 \% \\
\text { sensitive in determining fusion }\end{array}$ \\
\hline Patel et $\mathrm{al}^{35}$ & 2000 & Rabbits & $\begin{array}{l}\text { Single-level posterolateral } \\
\text { intertransverse process fusion } \\
\text { using either autograft or P-I, } \\
\text { followed by subcutaneous nicotine } \\
\text { administration via pumps }\end{array}$ & $\begin{array}{l}\text { Manual palpation, } \\
\text { radiographic evaluation, } \\
\text { biomechanical testing, } \\
\text { histological evaluation }\end{array}$ & $\begin{array}{l}\text { Superior fusion rate in OP-I + } \\
\text { nicotine group (100\%) vs } \\
\text { autograft + nicotine group ( } 25 \%)\end{array}$ \\
\hline $\begin{array}{l}\text { Cunningham } \\
\text { et }\left.a\right|^{36}\end{array}$ & 2000 & Canines & $\begin{array}{l}\text { Posterolateral arthrodesis using } \\
\text { either OP-I alone, iliac crest bone } \\
\text { autograft, or autograft + OP-I }\end{array}$ & $\begin{array}{l}\text { Radiographs, biomechanical } \\
\text { testing, } \\
\text { histopathological evaluation, } \\
\text { histomorphometric analysis }\end{array}$ & $\begin{array}{l}\text { Superior bone formation in both } \\
\text { OP-I groups vs autograft alone; } \\
\text { intramembranous ossification } \\
\text { mechanism in OP-I groups, } \\
\text { endochondral ossification in } \\
\text { autograft alone group }\end{array}$ \\
\hline $\begin{array}{l}\text { Paramore } \\
\text { et } \mathrm{al}^{37}\end{array}$ & 1999 & Canines & $\begin{array}{l}\text { Lumbar decompression with } \\
\text { dorsolateral fusion, with OP-I } \\
\text { placement in subarachnoid space } \\
\text { and in fusion bed in all patients }\end{array}$ & $\begin{array}{l}\text { Manual palpation, } \\
\text { radiographs, pathological } \\
\text { evaluation }\end{array}$ & $\begin{array}{l}\text { Bone formation occurred } \\
\text { in subarachnoid space in all } \\
\text { patients, causing mild stenosis; } \\
\text { no clinical/pathological features } \\
\text { of neurotoxicity found }\end{array}$ \\
\hline
\end{tabular}

demonstrating the potential of OP-1 to overcome nicotine inhibition.

As various experiments demonstrated equivalent or superior fusion rates with OP-1, the maturation process of lumbar posterolateral arthrodesis was not explored until Cunningham et al compared OP-1 versus autograft in the lumbar posterolateral arthrodeses in a canine model. ${ }^{36}$ Thirty-six dogs underwent surgery at L3-4 and L5-6, with fusion using either iliac crest bone autograft, autograft with OP-1 Putty, or OP-1 Putty alone. Superior bone formation and fusion was demonstrated in both OP-1 Putty groups compared to autograft. More importantly, different mechanisms of ossification were noted, with intramembranous ossification occurring in the OP-1 groups and endochondral ossification developing in the autograft group.

To assess the safety of OP-1 utilized in conjunction with lumbar decompression, Paramore and colleagues placed OP-1 in the subarachnoid space and in the fusion bed of thirty canines. ${ }^{37}$ Bone formed in the subarachnoid space in all animals treated with OP-1, contributing to mild stenosis postoperatively. However, no clinical or pathological features of neurotoxicity were noted.

\section{Early clinical efficacy studies and FDA approval}

Clinical investigations with human subjects were first reported in 1999, roughly 10 years after the initial use of purified human BMP was noted. Geesink et al examined the osteoinductive activity of OP-1 in humans in a prospective, randomized, double-blind study intended to evaluate the effectiveness of OP-1 on a collagen type-I carrier in criticallysized fibular defects. ${ }^{38}$ Twelve patients in the second phase of the experiment were divided into 2 groups, receiving either OP-1 on a collagen type-I carrier or the collagen carrier alone. After 6 weeks, new bone growth was initiated in 5/6 patients with OP-1 and none in the carrier alone group, thereby demonstrating the osteoinductive capacity of OP-1 in humans.

The FDA approval process began after a study by Friedlaender and colleagues. ${ }^{39}$ This large multicenter, 
partially blinded, randomized, prospective, controlled trial evaluated tibial nonunions treated with an intramedullary rod and either an OP-1/BMP-7 Implant (OP-1 $3.5 \mathrm{mg}$ and collagen carrier $1 \mathrm{~g}$ ) versus iliac crest autograft. Patients were divided into 2 groups and treated with either OP-1 in a type I collagen carrier or iliac crest bone graft. After clinical and radiographic evaluation at 9 months (and confirmed after 2 years), $81 \%$ of the OP- 1 treated tibial nonunions and $85 \%$ of those receiving autograft were judged by clinical criteria to have been treated successfully. Similarly, $75 \%$ of those treated with OP- 1 and $84 \%$ of patients treated with autograft were found radiographically to have healed fractures. These differences were not judged to be statistically significant, suggesting that OP-1 in a type I collagen carrier is a safe and effective treatment for tibial nonunions with a comparable effectiveness to autograft.

Following the study, the FDA in 2001 approved the OP-1 ${ }^{\circledR}$ Implant in the US under a Humanitarian Device Exemption (HDE). The approval was based upon the demonstration of safety of OP-1 and probable benefit to its usage, exempt from the more stringent Premarket Approval (PMA) requirement. PMA allows for product usage in an unlimited number of patients meeting the approved use, provided the product has demonstrated safety and effectiveness in clinical trials. The HDE endorsement, however, only allows for use in populations of less than 4000 patients per year to fill an unmet need - in this case, where previous treatments were unsuccessful and no other substitute exists. Institutional review board (IRB) approval is required at any site prior to usage under an HDE backing. Approved indications for use of the OP-1 Implant were as "an alternative to autograft in recalcitrant long bone nonunions where the use of autograft is unfeasible and alternative treatments have failed." ${ }^{29}$

After the conditional FDA approval was granted for the OP-1 Implant for treatment of tibial nonunions, a pilot study was begun to assess the effectiveness of OP-1 Putty in patients with grade I or II spondylolisthesis by Vaccaro and colleagues. Previously, the group had completed a significant clinical study regarding OP-1.40,41 The authors had demonstrated that OP-1 Putty used as an adjunct to autograft in treatment of a similar population of 12 patients with spondylolisthesis resulted in bridging bone formation in $70 \%$ of patients and clinically successful outcome (as measured by the Oswestry Disability Index) in $89 \%$ of patients, after 2-year follow-up. No toxicity, ectopic bone, or safety issues emerged. Thus, the implant was not judged to have superior efficacy to historical rates of autograft fusion alone; however, no adverse effects with usage were noted.
In the study performed after FDA approval, Vaccaro et al investigated the effectiveness OP- $1{ }^{\circledR} / \mathrm{BMP}-7$ Putty (OP-1, type I bovine collagen carrier, carboxymethylcellulose, saline) as a replacement to autograft, rather than in conjunction with autograft, in the treatment of patients with symptomatic grade I/II spondylolisthesis following spinal decompression. ${ }^{42}$ Thirty-six patients with neurogenic claudication and spondylolisthesis underwent decompressive laminectomy and one-level uninstrumented posterolateral fusion, using either OP-1 Putty or autograft. At 1-year follow-up, clinical success by the Oswestry scale was demonstrated in $86 \%$ percent of OP-1 patients versus $73 \%$ of autograft subjects. Similarly, fulfillment of criteria for successful radiographic fusion was found in $74 \%$ of OP-1 versus $60 \%$ of autograft patients. Statistical significance was not achieved with these numbers due to the small sample size. The authors concluded that fusion was obtained at a comparable rate by treatment with OP-1 Putty compared to autograft, without any adverse consequences. The results suggest OP-1 could represent an acceptable substitute to autograft in this application.

Based on the findings from the pilot study, the FDA in 2004 approved OP-1 Putty for use in patients undergoing revision posterolateral lumbar spinal fusion who suffer from factors that complicate healing or for whom autograft harvest is not feasible. ${ }^{29}$ Similar to 2001 , the 2004 endorsement was an HDE approval, which limited the number of patients per year for application to 4000 and mandated IRB agreement before use. Application is intended to meet the needs of those patients for whom bone graft use is not feasible during revision surgery. While the Vaccaro et al study was crucial in allowing the endorsement, a majority of the data used to justify approval was nonclinical, derived from spinal fusion studies on animal models (described previously). Therapeutic benefit and safety issues were projected from these paradigms, which only allowed for the limited HDE approval status.

\section{Pivotal trial of efficacy}

On account of the results from the prior pilot study, Vaccaro and colleagues undertook a large, prospective, randomized, controlled multicenter clinical trial on 295 patients to demonstrate the noninferiority of OP-1 versus autograft in patients with spondylolisthesis undergoing one-level posterior decompression and uninstrumented posterolateral intertransverse process arthrodesis. ${ }^{47}$ Patients were randomized 2:1 to receive OP-1 Putty versus iliac crest autograft. Overall treatment success was measured at 
24 months as a composite of several features: subjective pain and functional improvement $(>20 \%$ improvement on Oswestry Disability Index), radiographic spinal fusion (as judged by the presence of bridging bone on radiographs, $<5$ degrees angulation and $<2 \mathrm{~mm}$ translational motion on flexion-extension $x$-rays), absence of neurological status changes on exam (with the visual analog scale), and absence of retreatment. Notably, radiographic criteria were altered prior to closure of the database so that the "presence of bone" replaced the "presence of bridging bone" as an endpoint, and the definition of translational motion changed from " $<2 \mathrm{~mm}$ " to " $<3 \mathrm{~mm}$."

Results for the pivotal trial were compiled after 24 months. According to both the original and revised radiographic definitions, treatment by OP-1 Putty was not shown to be noninferior to conventional iliac crest autograft according to the composite overall success endpoint. Failure to demonstrate overall non-inferiority of OP-1 was primarily thought to be attributable to one parameter of the compositethe presence of bone as assessed by plain films. Radiographic results demonstrated the "presence of bone" in 51.9\% of OP-1 subjects, compared to $73.5 \%$ of autograft patients. This difference between plain film radiographic findings of fusion and clinical outcomes is particularly striking given the literature on the subject showing a high correlation between fusion and positive clinical outcomes in patients undergoing decompression with laminectomy. ${ }^{43,44}$ Comparable success between the OP-1 and autograft groups in the other radiographic parameters measuring stability of the fused level (angulation and translation) at 24 months was observed. Furthermore, the OP-1 Putty group achieved clinically comparable improvements in all other key clinical outcomes at 24 months postsurgery. OP-1 subjects also had statistically shorter operative times and less blood loss during surgery on average than autograft subjects.

In order to assess the validity of the plain film measurements at 24 months, the $\mathrm{x}$-rays were compared to CT scan results that were taken 9 months postoperatively but were not included in the original study. It was thought that if bridging bone was discovered by CT but missed by plain films in the OP-1 group, the presence of bridging bone might be comparable to that of the autograft group; consequently, the composite results might demonstrate noninferiority of the OP-1 group versus autograft. Review of the CT scans from 9 months postoperatively did, indeed, show the presence of bone missed by plain film, according to a 3-person panel of experts. The bridging bone was located medial to the transverse processes and bordering the lateral aspect of the facet joints. Such findings suggest that the plain films used to assess fusion at 24 months might not have been optimal in assessment of medial bone formation with OP-1 Putty. The reason for the irregularity might stem from the physical properties of OP-1 Putty. It had been previously assumed that OP-1 spurred bone growth in the same manner as autograft, laterally along the transverse processes. But it became clearer that the compressible, malleable OP-1 might perform differently than the sturdier, noncompressible autograft in vivo. Experts have suggested that when retractors are removed from the paraspinal musculature after placement of OP-1, the compressible putty may be shifted medially, causing medial bone formation (Figure 2). By this mechanism, OP-1 bone formation could escape detection on plain films and be underestimated as overlying organs, bowel, and bowel contents obscure new bone formation.

To fully assess bone growth by $\mathrm{CT}$ in a clinical trial format, Vaccaro and colleagues initiated an extension to the pivotal trial using 257 patients from the original patient population. ${ }^{29}$ OP-1 and autograft subjects were given a CT scan at 36 months to assess the degree of long-term bone formation at the graft sites, which was added to the 24 month clinical outcome data. The rationale for this mode of follow-up was that CT technology is more sensitive to bone growth and that a longer-term follow-up might offer a more accurate picture of bone formation. For overall treatment success, patients in both groups were also assessed for the absence of retreatment, based on 36 plus months' data. CT scans were assessed for "bridging bone," according to the original study protocol, but later revised to include formation of "any bone." Study results using "any bone" criteria on CT showed equal success $(47 \%)$ in both groups. Using the more stringent "bridging bone" as a definition of fusion, however, results showed superior results for autograft: $26 \%$ success in OP-1 patients compared to $36 \%$ in autograft. Therefore, using the original criteria of "bridging bone" to determine overall treatment success - and even after favoring CT scans for assessment OP-1 Putty was not found to be noninferior to autograft in the treatment of single level (L3-S1) degenerative spondylolisthesis (grade 1-2) in patients undergoing decompression and uninstrumented posterolateral lumbar fusion.

\section{Safety and tolerability of OP-I}

The safety profile of OP-1 in spinal fusion applications was demonstrated first in preclinical animal trials. To assess the safety of OP-1 utilized in conjuction with lumbar decompression, Paramore and colleagues placed OP-1 in the subarachnoid space and in the fusion bed of thirty canines. ${ }^{37}$ Bone formed 


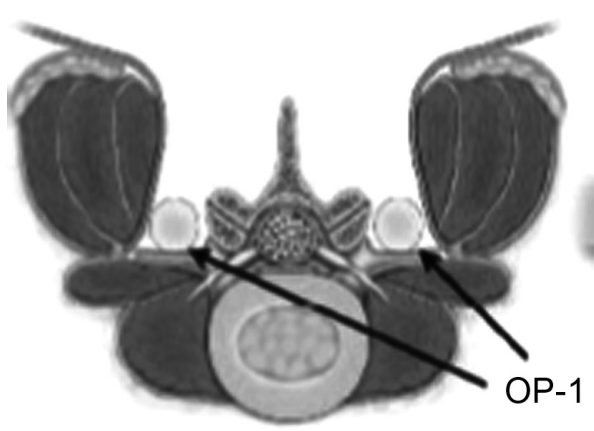

A

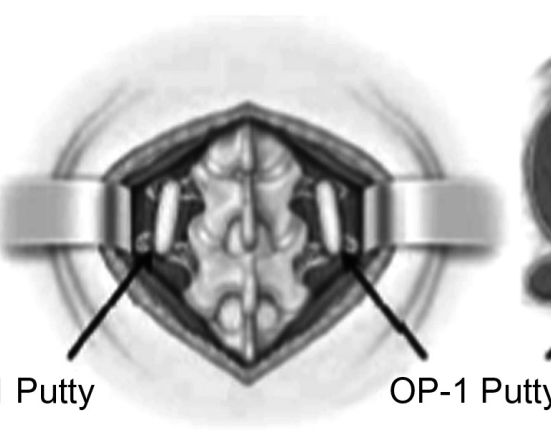

B

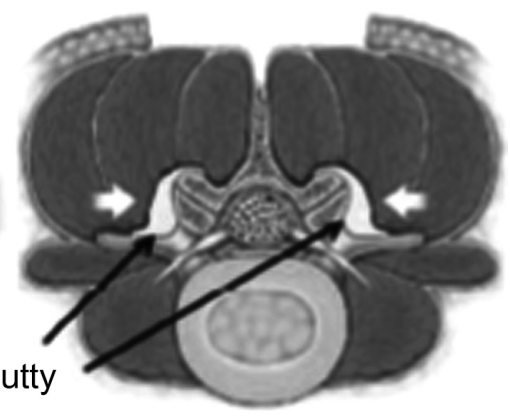

C

Figure 2 Schematic demonstrating the theoretical location of medial bone formation using OP-I after implantation. Reproduced with permission from Vaccaro AR, Lawrence JP, Patel T, et al. The safety and efficacy of OP-I (rhBMP-7) as a replacement for iliac crest autograft in posterolateral lumbar arthrodesis: a long-term ( $>4$ years) pivotal study. Spine. 2008;33:2850-2862. ${ }^{47}$ Copyright (C) 2008 Lippincott Williams \&Wilkins.

in the subarachnoid space in all animals treated with OP-1, contributing to mild stenosis postoperatively. However, no clinical or pathological features of neurotoxicity were noted.

In a review article examining the clinical safety of BMP for use in the spine, Poynton and Lane investigated the safety data for both BMP-2 and OP-1/BMP-7. ${ }^{45}$ The safety issues identified by the team for spinal applications included bony overgrowth, interaction with exposed dura, cancer risk, systemic toxicity, osteoclastic activation, and the effects on distal organs. Their investigation noted that while caution should be demonstrated in the application of these agents to prevent ectopic bone formation and further complications, both BMP-2 and OP-1 are well-tolerated when used appropriately. There was no evidence of carcinogenic activity or reproductive, systemic, or local toxicity in the trial data presented.

Human trials have also examined the safety associated with OP-1 use. In the clinical trials used to assess the safety of OP-1, there was no disparity between the number of adverse events or complications reported with OP-1 compared to autograft. Furthermore, there were no serious adverse events that were directly attributable to OP-1, even after several years of follow-up. ${ }^{42,46,47}$ Several clinical trials, however, have linked OP-1 use with the formation of reactive antibodies. These antibodies exist in 2 forms: as binding antibodies, which specifically bind to the target molecule (in this case OP-1); and neutralizing antibodies, a subset of the binding antibodies that inhibits the target molecule's impact, thereby interfering at least to some degree in the receptor ligand-interaction. Geesink et al investigated the formation of an immunologic response in treatment of fibular defects, finding no formation of antibodies against OP- $1 .{ }^{38}$
Friedlaender et al however, reported a $10 \%$ incidence of anti-OP-1 antibodies in patients treated with OP-1 for tibial nonunions. These antibody titers were low and transient, marked by no adverse events. ${ }^{39}$

In the recent pivotal trial completed by Vaccaro and colleagues, the role of these antibodies was examined in patients undergoing single-level uninstrumented posterolateral arthrodesis for spinal stenosis and spondylolisthesis. ${ }^{47}$ The presence of both binding and neutralizing antibodies were examined in OP-1 subjects. A high number of OP-1 patients were discovered to have antibodies: 94\% of OP-1 Putty subjects were positive compared to $21 \%$ of autograft patients. Antibody titers were most frequent between 6 weeks and 3 months. After 12 months, however, no patients in either group demonstrated the presence of neutralizing antibodies. Importantly from a clinical standpoint, no association existed between neutralizing activity and clinical outcome as clinical success of patients with neutralizing activity (36\%) was not statistically significant from the overall success of those without detectable neutralizing activity (38\%). Nevertheless, the continued presence of binding antibodies (37\% of OP-1 patients after 36 months) remains of clinical concern in the future as their function and activity have not yet been characterized.

\section{Cost-effectiveness}

Several economic evaluations have compared the cost of BMP use with the cost of traditional autogenous iliac crest bone grafting. ${ }^{48-50}$ Most investigations have concluded that BMPs such as OP-1/BMP-7 are cost neutral, compared to iliac crest autograft. The costs associated with BMP use are offset by the prevention of pain and complications associated with obtaining the iliac crest graft. The upfront price of BMPs is 
likely counterbalanced by the reduction in the use of medical resources, primarily by decreasing the number of necessary revisions and increasing the number of successful fusions. ${ }^{48}$ A key point from the study is that the cost effectiveness is strongly tied to the price of BMP. Price changes will surely occur in the future as new technologies emerge and are replaced, which could affect clinical decision-making with respect to OP-1 use. Another study established an economic model based on clinical trial data, clinical expert opinion, and peer-reviewed literature that proposed BMP costs are offset over the first 2 years after surgery by a more efficient use of other medical resources, such as a decreased length of hospital stay and decreased use of pain clinics. ${ }^{49} \mathrm{~A}$ randomized control trial investigating the economic benefit of OP-1 use in patients undergoing spinal fusion for spondylolisthesis is lacking. However, a randomized, control trial examining the use of BMP-2 in 102 patients undergoing lumbar spine surgery found a cost reduction associated with the substitute instead of iliac crest bone graft. The study calculated costs associated with surgery, the hospital study, and first 3 months of recovery in those two groups, finding the average cost in the BMP-2 group (US\$33,860) to be lower than that in the autograft group (US\$37,227). A similar investigation related to OP-1 use is currently warranted.

\section{Legal concerns}

Stryker Corporation, the distributor of the OP-1 Implant and OP-1 Putty, is currently facing a federal probe related to the use of its bone growth products. Since November 2008, 3 sales representatives have pled guilty to promoting the off-label use of OP-1 products. In March 2009, a federal investigation of the company was begun to examine claims of misbranding of the OP-1 products outside of their HDE status. As part of plea deals, representatives have claimed that they had encouraged medical professionals to combine OP-1 products, even though they knew doing so was not approved by the FDA and had resulted in adverse events. Prosecutors stated that other company employees distributed brochures providing instructions for mixing bone products in ways not approved by the FDA. ${ }^{51}$ Previously, in July 2008 the FDA warned that the OP-1 Implant and OP-1 Putty had been linked to potentially fatal complications when used in off-label cervical spinal fusions. Swelling of the neck and throat tissues had been reported in 38 separate patients over a 4-year span, leading to compression of the airway and neural structures that necessitated emergency surgical intervention. ${ }^{52}$ Investigations into the off-label use of OP-1 as well as its potentially serious consequences are ongoing.

\section{Future considerations}

After completion of the pilot and pivotal trials investigating the use of OP-1 in patients undergoing spinal fusion for grade I/II spondylolisthesis, approval for more widespread use was sought by the product's proprietary owners (Stryker Biotech, Hopkington, MA, USA). FDA approval in 2001 had granted limited use for tibial nonunions and in 2004 for revision posterolateral spinal fusion in complicated patients, both under an HDE. OP-1 Putty is currently marketed under the HDE for use in fewer than 4000 patients yearly. Further approval, however, appears difficult as a result of the pivotal trial completed by Vaccaro et al. As discussed previously, this randomized multicenter clinical trial did not demonstrate the noninferiority of OP-1 compared to iliac crest autograft, in large part due to the inability to detect bone fusion on radiographs taken 24 months postoperatively.

Citing the recent trial, an FDA advisory panel (April 2009) recently advised against the Premarket Approval (PMA) of the OP-1 Putty. The FDA panel cited several reasons for its disapproval: the use of post-hoc analysis to bias the study results, introducing type I errors; the radiographic marker of "bone" was not equivalent to "bridging bone," as the former could represent fibrous tissue formation; the patient population was representative of a "stiff population" at baseline; and lastly, the immunologic effects of antibody formation against the protein were not known. These findings led to the overall panel decision to reject the PMA approval of OP-1 in its current form. Any approval at this point would likely require a new clinical trial and further investigation of its immunologic consequences.

Meanwhile, investigations of OP-1 and its optimal method of clinical application are ongoing. Impressive results in animal models have yet to be repeated successfully in humans, a result that could be due to a variety of factors. The recruitment of bone precursor cells and bone turnover may be different in animals, and illumination of this pathway could lead to a greater insight into the biochemical mechanism in humans. Furthermore, the ideal dosing concentrations used in BMP clinical applications are not known and are currently being investigated. ${ }^{25}$ It is possible that many current formulations of OP-1 are supraphysiologic, and BMP inhibitors (eg, noggin or sclerotin) that are upregulated by BMP presence may be contributing to a negative feedback loop that interferes with bodily healing mechanisms. Lastly, investigations into the use of "cocktails" of different BMPs, with either simultaneous or sequential release, instead of OP-1 alone to promote bone healing are ongoing. ${ }^{53}$ 


\section{Conclusion}

Since their discovery in 1965, BMPs such as OP-1 have been subject to significant clinical interest for their medical applications. Understanding their biochemical structure and physiologic role as members of the TGF- $\beta$ family has shed light on their role as an initiators of bone growth. Promising findings in animal studies and early clinical trials with OP-1 prompted FDA approval for use in long bone nonunions in 2001 and subsequently for revision posterolateral arthrosis in 2004 under a conditional Humanitarian Device Exemption. Larger clinical trials have recently shown no notable safety concerns or increases in adverse events associated with OP-1. However, a recent clinical trial has not conclusively demonstrated the noninferiority of OP-1 compared to autograft in revision posterolateral arthrodesis. The future of OP-1 application in patients with spondylolisthesis thus remains uncertain with the recent rejection of Premarket Approval (PMA) status by the FDA (April 2009), which prevented wider product usage in any patient approved for its use. Further investigation of its treatment success and immunological consequences appears warranted to establish FDA approval for its use in its current form.

\section{Disclosure}

Kern Singh is a consultant for Depuy Spine, Styrker Spine, and Pioneer Surgical. No financial or material support was provided for this study.

\section{References}

1. Cotler JM, Star AM. Complications of spinal fusion. In: Cotler JM, Cotler HB, eds. Spine fusions: Science and Technique. New York: Springer-Verlag, 1990.

2. Watkins MB, Bragg C. Lumbosacral fusion: Results with early ambulation. Surg Gynecol Obstet. 1956;102:605.

3. Cockin J. Autologous bone grafting: Complications at the donor site. J Bone Joint Surg. 1971;52:153.

4. Younger EM, Chapman MW. Morbidity at bone graft donor site. J Orthop Trauma. 1989;3:192-195.

5. Urist MR. Bone: Formation by autoinduction. Science. 1965;150: 893-899.

6. Reddi AH. Cell biology and biochemistry of endochondral bone development. Collagen Rel Res. 1981;1:209-226.

7. Wozney JM, Rosen V, Celeste AJ, et al. Novel regulators of bone formation: Molecular clones and activities. Science. 1988;242: 1528-1534.

8. Alden T, Varady P, Kallmes DF, et al. Bone morphogenetic protein gene therapy. Spine. 2002;27(16S):S87-S93.

9. Wozney JM. Overview of bone morphogenetic proteins. Spine. 2002;27(16 Suppl 1):S2-S8.

10. Israel DI, Nove J, Kerns KM, et al. Heterodimeric bone morphogenetic proteins show enhanced activity in vitro and in vivo. Growth Factors. 1996;13:291-300.

11. ten Dijke P, Fu J, Schaap P, et al. Signal transduction of bone morphogenetic proteins in osteoblast differentiation. J Bone Joint Surg. 2003;85-A Suppl 3:34-38.
12. Ebara S, Nakayama K. Mechanism for the action of bone morphogenetic proteins and regulation of their activity. Spine. 2002;27 (16S):S10-S15.

13. Valentin-Opran A, Wozney J, Csimma C, et al. Clinical evaluation of rhBMP-2. Clin Orthop Relat Res. 2002;3:79-83.

14. Celeste AJ, Iannazzi JA, Taylor RC, et al. Identification of transforming growth factor beta family members present in bone-inductive protein purified from bovine bone. Proc Natl Acad Sci U S A. 1990; 87:9843-9847.

15. Ducy P, Karsenty G. The family of bone morphogenetic proteins. Kidney Int. 2000;57:2207-2214.

16. Jena N, Martin-Seisdedos C, McCue P, et al. BMP7 null mutation in mice: Developmental defects in skeleton, kidney, and eye. Exp Cell Res. 1997;230: 28-37.

17. Luo G, Hoffmann C, Bronckers ALJJ, et al. BMP-7 is an inducer of nephrogenesis, and is also required for eye development and skeletal patterning. Genes Dev. 1995;9:2808-2820.

18. Helm G, Anderson DG, Andersson GBJ, et al. Summary statement: bone morphogenetic proteins. Spine. 2002;27(16 Suppl):S9.

19. Reddi AH. Role of morphogenetic proteins in skeletal tissue engineering and regeneration. Nat Biotechnol. 1998;16:247-252.

20. Lu J, Bhargav D, Wei AQ, Diwan A. Posterolateral intertransverse spinal fusion possible in osteoporotic rats with BMP-7 in a higher dose delivered on a composite carrier. Spine. 2008;33:242-249.

21. Grauer JN, Vaccaro AR, Kato M, et al. Development of a New Zealand rabbit model of spinal pseudoarthrosis repair and evaluation of the potential role of OP-1 to overcome pseudoarthrosis. Spine. 2004;29:1405-1412.

22. Moazzaz P, Gupta MC, Gilotra MM, et al. Estrogen-dependent actions of bone morphogenetic protein-7 on spine fusion in rats. Spine. 2005;30:1706-1711.

23. Patel TC, Erulkar JS, Grauer JN, Troiano NW, Panjabi MM, Friedlaender GE. Osteogenic protein-1 overcomes the inhibitory effect of nicotine on posterolateral lumbar fusion. Spine. 2001;26:1656-1661.

24. Brown A, Stock G, Patel AA, Okafor C, Vaccaro A. Osteogenic protein-1: a review of its utility in spinal applications. BioDrugs. 2006;20:243-251

25. Bessa PC, Casal M, Reis RL. Bone morphogenetic proteins in tissue engineering: the road from laboratory to clinic, part II (BMP delivery). J Tissue Eng Regen Med. 2008;2:81-96.

26. Sandhu HS. Bone morphogenetic proteins and spinal surgery. Spine. 2003;28(Suppl 15):S64-S73.

27. Boden SD, Martin GJ Jr, Morone M, Ugbo JL, Titus L, Hutton WC. The use of coralline hydroxapatite with bone marrow, autogenous bone graft, or osteoinductive bone protein extract for posterolateral lumbar spine fusion. Spine. 1999;24:320-327.

28. Uludag H, Friess W, Williams D, et al. RhBMP-collagen sponges as osteoinductive devices: effects of in vitro sponge characteristics and protein pI on in vivo rhBMP pharmacokinetics. Ann N Y Acad Sci. 1999; 875:369-378.

29. Stryker Corporation. OP-1 Putty. PowerPoint Presentation. January 2009.

30. Schimandle JH, Boden SD. The use of animal models to study spinal fusion. Spine. 1994;19:1998-2006.

31. Sandhu HS, Khan SN. Animal models for preclinical assessment of bone morphogenetic proteins in the spine. Spine. 2002;27(Suppl 16):S32-S38.

32. Cook SD, Wolfe MW, Salkeld SL, et al. Effect of recombinant human osteogenic protein-1 on healing of segmental defects in non-human primates. J Bone Joint Surg Am. 1995;77:734-750.

33. Magin MN, Delling G. Improved lumbar vertebral interbody fusion using rhOP-1: a comparison of autogenous bone graft, bovine hydroxylapatite (Bio-Oss), and BMP-7 (rhOP-1) in sheep. Spine. 2001;26:469-478.

34. Grauer JN, Patel TC, Erulkar JS, et al. 2000 Young Investigator Research Award winner. Evaluation of OP-1 as a graft substitute for intertransverse process lumbar fusion. Spine. 2001;26:127-133.

35. Patel TC, Erulkar JS, Grauer JN, et al. Osteogenic protein-1 overcomes the inhibitory effect of nicotine on posterolateral lumbar fusion. Spine. 2001;26:1656. 
36. Cunningham BW, Shimamoto N, Sefter JC, et al. Osseointegration of autograft versus osteogenic protein-1 in posterolateral spinal arthrodesis: emphasis on the comparative mechanisms of bone induction. Spine J. 2002;2:11-24.

37. Paramore CG, Lauryssen C, Rauzzino MJ, et al. The safety of OP-1 for lumbar fusion with decompression: a canine study. Neurosurgery. 1999;44:1151-1155.

38. Geesink RG, Hoefnagels NH, Bulstra SK. Osteogenic activity of OP-1 bone morphogenetic protein (BMP-7) in a human fibular defect. J Bone Joint Surg Br. 1999;81:710-718.

39. Friedlaender GE, Perry CR, Cole JD, et al. Osteogenic protein-1 (bone morphogenetic protein-7) in the treatment of tibial nonunions. $J$ Bone Joint Surg Am. 2001;83-A Suppl 1 (Pt 2):S151-S158.

40. Vaccaro AR, Patel T, Fischgrund J, et al. A pilot safety and efficacy study of OP-1 putty (rhBMP-7) as an adjunct to iliac crest autograft in posterolateral lumbar fusions. Eur Spine J. 2003;12:495-500.

41. Vaccaro AR, Patel T, Fischgrund J, et al. A 2-year follow-up pilot study evaluating the safety and efficacy of OP-1 putty (rhBMP-7) as an adjunct to iliac crest autograft in posterolateral lumbar fusions. Eur Spine J. 2005;13:623-629.

42. Vaccaro AR, Patel T, Fischgrund J, et al. A pilot study evaluating the safety and efficacy of OP-1 putty (rhBMP-7) as a replacement for iliac crest autograft in posterolateral lumbar arthrodesis for degenerative spondylolisthesis. Spine. 2004;29:1885-1892.

43. Lombari JS, Wiltse LL, Reynolds J, Widell EH, Spencer C. Treatment of degenerative spondylolisthesis. Spine. 1985;10:821-827.

44. Johnsson KE, Redlund-Johnell I, Uden A, Willner S. Preoperative and postoperative instability in lumbar spinal stenosis. Spine. 1989; 14:591-593.

45. Poynton AR, Lane JM. Safety profile for the clinical use of bone morphogenetic proteins in the spine. Spine. 2002;27(16 Suppl 1): S40-S48.
46. Vaccaro AR, Patel T, Anderson DG, et al. Comparison of OP-1 putty (rhBMP-7) to iliac crest autograft for posterolateral lumbar arthrodesis: a minimum 2-year follow-up pilot study. Spine. 2005;30: 2709-2716.

47. Vaccaro AR, Lawrence JP, Patel T, et al. The safety and efficacy of OP-1 (rhBMP-7) as a replacement for iliac crest autograft in posterolateral lumbar arthrodesis: a long-term ( $>4$ years) pivotal study. Spine. 2008;33:2850-2862

48. Ackerman SJ, Mafilios MS, Polly DW Jr. Economic evaluation of bone morphogenetic protein versus autogenous iliac crest bone graft in single-level anterior lumbar fusion: an evidence-based modeling approach. Spine. 2002;27(16 Suppl 1):S94-S99.

49. Polly DW Jr, Ackerman SJ, Shaffrey CI, et al. A cost analysis of bone morphogenetic protein versus autogenous iliac crest bone graft in single-level anterior lumbar fusion. Orthopedics. 2003;26: 1027-1037.

50. Glassman SD, Carreon LY, Campbell MJ, et al. The perioperative cost of Infuse bone graft in posterolateral lumbar spine fusion. Spine J. 2008;8:443-448.

51. Stryker Corp. says it faces federal probe over OP-1 and Calstrux products NewsInferno.com. http://www.newsinferno.com/archives/5023. Published March 11, 2009. Accessed July 7, 2009.

52. FDA issues warning about unapproved use of recombinant human bone morphogenetic protein in cervical spine fusions. MD Consult. http://www.mdconsult.com/das/news/body/148179290-2/ drug/0/197308/1.html?pos=fdasafety. Published July 11,2008. Accessed July 7, 2009.

53. Hadjiargyrou M, Lombardo F, Zhao S, et al. Transcriptional profiling of bone regeneration. Insight into the molecular complexity of wound repair. J Biol Chem. 2002;277:30177-30182.

54. Walker DH, Wright NM. Bone morphogenetic proteins and spinal fusion. Neurosurg Focus. 2003;13:1-13.
Orthopedic Research and Reviews

\section{Publish your work in this journal}

Orthopedic Research and Reviews is an international, peer-reviewed, open access journal that focusing on the patho-physiology of the musculoskeletal system, trauma, surgery and other corrective interventions to restore mobility and function. Advances in new technologies, materials, techniques and pharmacological agents are particularly welcome. The journal welcomes

\section{Dovepress}

original research, clinical studies, reviews \& evaluations, expert opinion and commentary, case reports and extended reports. The manuscript management system is completely online and includes a very quick and fair peer-review system, which is all easy to use. Visit http://www.dovepress. com/testimonials.php to read real quotes from published authors. 